\title{
TRAJETÓRIA CONTEMPORÂNEA EM TERRITÓRIOS AFRICANOS: AS EXPERIÊNCIAS ROMANESCAS DE PAULINA CHIZIANE EM MOÇAMBIQUE E SEFI ATTA NA NIGÉRIA
}

Stela Saes

Resumo: Este artigo destina-se a apresentar um panorama do projeto literário contemporâneo das escritoras Paulina Chiziane de Moçambique e Sefi Atta da Nigéria, concentrando-se nos romances publicados por elas entre a década de 90 e anos 2000. O objetivo é demonstrar de que forma ambas posicionam o projeto político de seus escritos ficcionais, centrando as mulheres em suas demandas e lutas nos territórios africanos da contemporaneidade. Essa perspectiva é possível pois, enquanto autoras comprometidas com os processos de escrita ficcional, cujas condições materiais recaem de maneira política, econômica e social nas narrativas por elas colocadas, uma análise materialista da literatura é capaz de organizar os embates perpetrados pelas trajetórias das personagens e das escritoras enquanto agentes políticos. Ao analisar as experiências romanescas das escritoras, as imbricações entre feminismo, história e literatura revelam-se presentes, pois evidencia-se que a própria existência dessas escritoras e seus textos em um universo colonial, racista, patriarcal e capitalista que oprime constantemente suas mais variadas formas de expressão, é determinante para a consolidação de seus escritos ficcionais.

Palavras-chave: Literaturas africanas. Paulina Chiziane. Sefi Atta. Escrita Feminina. Romance.

Abstract: This paper aims to present an overview of the contemporary literary project about the writers Paulina Chiziane, from Moçambique and Sefi Atta, from Nigeria, focusing on the novels published by them between the 90 s and 2000s. The objective is to demonstrate how both of them place the political projects in their ficctional writings, centering the women in their demands and struggles in the African territories in the contemporaneity. This perspective is possible because, as authors committed to the process of fictional writing, whose material conditions fall politically, economically and socially in their narratives, a materialistic analysis of the literature is able to organize the struggles 
perpetraded by the trajectories of the novel characters and writers as political agents. When analysing the writers' novelistic experiences, the imbrications between feminism, history and literature are showed, because the existence of these writers and their writings in a colonial, racist, patriarchal and capitalist universe that constantly oppresses their different ways of expression, are decisive to the consolidation of their ficcional writings.

Keywords: African Literature. Paulina Chiziane. Sefi Atta. Female Writing. Novel.

\section{CONSIDERAÇÕES INICIAIS}

À medida que a literatura, como produto cultural, é constituída a partir de uma dada conjuntura, o texto está em constante relação dialética com seu tempo, espaço e condições de produção, de maneira que se constitui como força de expressão, pois a linguagem mobilizada esteticamente emerge as contradições de seu contexto histórico. Nesse sentido, é mais do que necessário perceber quais são as reais circunstâncias de trabalho no tocante às escritoras, o que pode ser vislumbrado - de maneira pioneira - mediante às reflexões de Virgínia Woolf em Um teto todo seu (1929), em que ela assinala, a partir da imagem da suposta irmã de Shakespeare, a desvantagem material e histórica para que mulheres possam escrever ficção ainda no início do século XX.

Além de não conseguirem obter condições mínimas e repertório sociocultural para o exercício da ficção, o legado, 
até então, no mundo ocidental, era de que as mulheres que desejavam escrever eram, muitas vezes, proibidas por seus familiares, evitadas pelos editores e repudiadas por jornais. Mesmo com inúmeras adversidades, grande parte daquelas com acesso à educação, no seio da classe burguesa, foram grandes leitoras, que ajudaram, inclusive, a consolidar o gênero romance durante o século XVIII e XIX. No entanto, vale lembrar, elas também sempre foram autoras, e, escrevendo, cometiam enormes transgressões; as que ousavam publicar usando seus próprios nomes recebiam muitas críticas, eram excluídas socialmente ou desconsideradas para o casamento pois extrapolavam o papel designado a elas. Recorrer aos pseudônimos, muitas vezes, era necessário justamente para evitar a exposição pública ou para agradar os editores da época, como foi o caso de Mary Ann Evans assinando suas obras como Georg Eliot.

Assim, mulheres que, de alguma forma, estão ligadas à intelectualidade sempre foram mal vistas na sociedade. Em contexto brasileiro, Clarice Lispector - que também iniciou sua carreira com o uso de pseudônimo e acrônimos $^{1}$-, em seu conto "Amor"2, retrata a quão perigosa pode ser a hora em que a mulher começa a pensar, pois, refletindo, ela pode

1 NUNES, Maria Aparecida. "Dissimulações de Clarice Lispector". Olho d'água, São José do Rio Preto, n. 2, v. 2, p. 66-67, 2010.

2 LISPECTOR, Clarice. "Amor" In: Laços de Família. Rio de Janeiro: Rocco, 1998. 
recusar todos os papéis que foram implantados ao gênero e abandonar aquela vida socialmente imposta da mãe, dona de casa e esposa. Nesse sentido, mulheres que escrevem, pensam, produzem arte e pensamento científico eram - e ainda são - vistas como transgressoras da ordem natural e do lugar que devem, tradicionalmente, ocupar na sociedade.

Além disso, vale lembrar outro aspecto condicionante à escrita feminina que ainda incide atualmente: a de que existe uma separação entre obras feitas por e para mulheres em oposição a obras universais, as quais são lidas por todos os gêneros. Ao partir dessa premissa, toda escritora poderia se dedicar apenas a "assuntos de mulheres". Nessa perspectiva, muitas ainda são recusadas editorialmente quando ousam retratar histórias de outros campos que não estejam ligados, sobretudo, ao amor. Nessa perspectiva, uma experiência realizada pela escritora norte-americana Catherine Nichols em $2015^{3}$ e levantamentos da organização americana VIDA - Women in Literary Arts, revelaram que muitas mulheres deixam de publicar seus livros ou sofrem pressões nas editoras, submetendo-se a mudança de capas, títulos e até nome de autoria para serem aceitas.

3 NICHOLS, Catherine. "Homme de Plume: What I Learned Sending My Novel Out Under a Male Name" In: JEZEBEL: A Supposedly Feminist Website. Disponível em: https://jezebel. com/homme-de-plume-what-i-learned-sending-my-novel-out-und-1720637627 Acesso em 03 mar. 2020. 
A problemática levantada pelas pesquisas levanta também a ideia de que poderia existir alguma especificidade na ficção produzida por mulheres. Hipótese que é refutada por Virginia desde o princípio de seu ensaio justamente pela desigualdade nas oportunidades de escrita daquela época. Ao propor que imaginemos Judith, a irmã de Shakespeare igualmente talentosa, ela afirma que enquanto o escritor da língua inglesa recebia as tratativas necessárias para exercer sua profissão, “[...] sua extraordinariamente bem dotada irmã, suponhamos, permanecia em casa" (WOOLF, 2014, p. 73), estaria à espera do casamento com um homem escolhido pelo seu próprio pai e, mesmo que se revoltasse contra os deveres sociais da época, ao contrário do irmão, não conseguiria espaço de atuação profissional. A história narrada por Woolf acaba com Judith grávida e cometendo suicídio, imagem trágica que faz com que pensemos sobre a realidade de tantas mulheres que tiveram suas trajetórias desconhecidas pelas condições materiais que a imposição patriarcal as submeteu.

Apesar de sempre existirem autoras que conseguiram adentrar as lacunas do sistema que as oprimia, as condições para que uma mulher pudesse se sustentar por esse ofício eram distantes do ideal e necessário. Desde os 
apontamentos da escritora inglesa, as mulheres, inclusive as mulheres negras, avançaram consideravelmente no ofício da escrita. Mas enquanto ainda sofrem o machismo presente até hoje para as publicações editoriais, as forças de opressão, violência e silenciamento de mulheres ainda acontecem de maneira sistemática e, por isso, sempre serão tematizadas pela literatura feita por elas.

Pensando, a partir das reflexões iniciais, nas diversas sociedades e tempos históricos estabelecidos desde então - se para determinadas classes e raças de mulheres houve certas conquistas no campo da leitura e da escrita mesmo que não em condições ideais ou de igualdade, para outras, as impossibilidades ainda são, de fato, condicionantes. Nesse sentido, é certo que as próprias condicionantes da imposição patriarcal devem permear a obra literária e o projeto de escrita das mulheres das mais variadas formas, denunciando uma socialização distinta que é marcada pelo machismo das estruturas e das relações, somando-se ainda ao racismo e ao colonialismo dentro da lógica sistemática capitalista do mundo contemporâneo.

Cabe, portanto, neste ponto, investigar os casos de Paulina Chiziane em Moçambique e Sefi Atta na Nigéria, refletindo de que maneira as condições materiais recaem 
sobre o processo de escrita ficcional dessas mulheres africanas na contemporaneidade e como se expressam dentro das trincheiras políticas e econômicas sobre as quais estão colocadas.

\section{LITERATURAS AFRICANAS DE MULHERES CONTEMPORÂNEAS}

Durante a última década, as publicações de obras ficcionais ou não - de mulheres africanas cresceram substancialmente. Talvez, quando pensamos nesse cenário, um dos nomes mais aclamados dentro e fora do contexto referido seja o da nigeriana Chimamanda Ngozi Adichie que, após escrever ficção e se apresentar em algumas conferências muito bem recebidas e compartilhadas pelo mundo todo ${ }^{4}$, deixou como legado um nome marcante para a literatura nigeriana e quiçá para todo o continente. $\mathrm{Na}$ esteira de Chimamanda, carregam-se outros tantos nomes da escrita romanesca visibilizados e, atualmente, mais acessíveis, como: Buchi Emecheta (nigeriana), Scholastique Mukasonga (Ruanda), Yaa Gyasi (Gana) e Rutendo Tavengerwei (Zimbábue) ${ }^{5}$, além de tantos outras ainda não são editados ou traduzidos fora dos limites de cada nação.

4 Suas conferências mais conhecidas no canal TEDTalks são nomeadas "The danger of a single story" de 2009 e "We should all be feminist" de 2013. Ambas foram transformadas em texto, já traduzidas e publicadas pela Companhia das Letras no Brasil.

5 Todas foram publicadas no Brasil. 
Talvez, grande parte dessa explosão de publicações de mulheres africanas no Brasil durante a última década caminhe na esteira das conquistas gestadas no âmbito da Lei 10.639/03 (posteriormente alterada para Lei 11.645/11). Após quase vinte anos de sua aprovação, um novo paradigma consolidou-se como conquista importantíssima para a educação brasileira, ligando-se também à literatura, pois ofereceu maior amparo e campo para publicações e engajamentos ligados à cultura e história africana e afrobrasileira, em escolas públicas, particulares e no acesso e pesquisa em universidades. O resultado do movimento negro brasileiro, desde a década de cinquenta, trouxe muito trabalho e enfrentamento para reorganizar a ordem de poder estabelecida dentro das fissuras e contradições do sistema vigente e trouxe resultados evidentes.

Nesse sentido, é necessário que a maior publicação e consumo mercadológico de literaturas africanas seja acompanhado também pelo movimento comprometido da crítica, pois, dado que a literatura deve ser compreendida como manifestação estética e artística em termos dos contextos históricos que a produzem, não se pode perder de vista as próprias condições de tempo e espaço da crítica literária (EAGLETON, 2011, p. 08). Por isso, cabe também 
refletir sobre a questão da autonomia relativa da obra literária, já que a escrita ficcional é produzida a partir de um campo ideológico relacionado a uma estrutura material determinada economicamente e historicamente, sendo o papel da crítica engajada o de justamente participar, de maneira contributa, com o significado das contradições de seu próprio tempo histórico.

Por tais razões, é preciso encarar as publicações de mulheres oriundas do continente africano com determinada especificidade e saber que a presença recente em livrarias e os estudos críticos a respeito, ainda são insuficientes para abarcar a dimensão de escritoras que não conseguem publicar seus textos em seus países de origem e que, infelizmente, ainda são poucas, numericamente, que se lançam ao ofício. Nesse sentido, além do papel da dominação patriarcal ${ }^{6}$, a questão racial e a realidade colonial e globalizante trazem inúmeros desafios que são também revelados na tessitura das obras literárias, no sentido de que a escrita feminina é engajada com sua própria condição de resistência e enfrentamento de tais estruturas.

\footnotetext{
6 Aqui, o conceito de dominação patriarcal é baseado nas exposições de Heleieth Saffiotti que o determina como um sistema de dominação e exploração de homens sobre as mulheres que é anterior ao capitalismo, mas que se mantém sobre ele e, como consequência, o ajuda a se manter. Para a teórica brasileira, é imprescindível também analisar o patriarcado e o capitalismo na simbiose com o racismo, como sistema de dominação e exploração do branco sobre o negro, já que essas esferas atuam de maneira diferente sobre mulheres brancas e negras. SAFFIOTTI, Heleieth. Gênero, patriarcado e violência. São Paulo: Editora Expressão Popular, 2004.
} 
Nos territórios africanos, a escrita das mulheres foi - e ainda é -, tantas vezes, interditada ou relegada às margens da literatura produzida por homens, principalmente quando nos debruçamos sobre o gênero literário romance. Por ser a forma ficcional que mais possibilita a observação da trajetória e transformação das personagens e, por isso, projeta a capacidade de mudança e atuação dentro de determinado tempo e espaço, escrever sob essa forma e na língua dos colonizadores foi um importante passo, para consolidar para além dos territórios em si, as imagens das novas nações à luz dos processos de independência pelo continente a partir de meados do século XX. Esse grande projeto, no entanto, esteve vinculado estreitamente às experiências masculinas, conforme destaca Stratton (1994).

Nesse sentido, a forma estética por excelência de nosso tempo (LUKÁCS, 1999), o romance, tal como conhecemos hoje, parte dos anseios burgueses ocidentais e se configura como possibilidade de contestação do sistema globalizado vigente, que é capitalista, colonial, racista e patriarcal. Para as mulheres, no entanto, suas participações nas camadas históricas de libertação e construção de um novo mundo foram, muitas vezes, silenciadas ou colocadas em segundo plano, inclusive dos processos de lutas armadas e ideais 
nacionalistas ${ }^{7}$. É fato que, tanto a experiência colonial, quanto a independência e o contexto pós esses eventos históricos são vivenciados de maneira distinta por homens e mulheres e, por isso, a literatura pode trazer composições de resistência de enfrentamento diversos para essas narrativas. Por tais motivos é que a escrita, a produção e a leitura deste gênero possibilitam às mulheres o grande exercício da ficção, pois a ideia de uma mulher escrever um texto literário comprometido, traz sempre um outro olhar que se compõe às narrativas já estabelecidas.

Porém, o acesso aos meios que possibilitam o exercício da escrita não é democratizado a toda a população de maneira igualitária. A educação formal, como destacam Soares e Carbonieri (2016) a partir dos estudos de Brown e Stratton, também foi e ainda é determinante para a acessibilidade da escrita para mulheres:

Brown e Stratton elencam, como uma das razões principais para o reduzido número de escritoras na África, se comparado ao de autores homens, o fato de não ter havido, até recentemente, uma equidade de oportunidades educacionais para homens e mulheres na África. Se alfabetizar-se já

7 Aqui caberia destacar a grande importância de mulheres angolanas e moçambicanas na luta armada e que são pouco retratadas em obras literárias. Além de Paulina Chiziane com Ventos do Apocalipse, há poucas menções a essas mulheres na ficção. Em uma obra mais divulgada e reconhecida, Ondina, presente em Mayombe de Pepetela, talvez represente timidamente a presença feminina na história de libertação nacional. 
era uma experiência rara para as mulheres, graduar-se numa universidade era ainda mais difícil. $\mathrm{E}$ a educação superior tem sido, como sabemos, uma das características mais recorrentes nos autores africanos que se dedicam a escrever nas línguas europeias. (SOARES; CARBONIERI, 2016, p. 138)

O acesso, portanto, à outras literaturas e à alfabetização na língua do colonizador é fundamental para que um projeto literário feminino seja esboçado e continuado nos países africanos. No caso dos romances produzidos nos continentes e reconhecidos pelo mundo, a apropriação da língua é fator essencial para que este seja lido, editado e, no caso de outros idiomas que não o português, também sejam traduzidos. 0 acesso à escola, torna-se, desse modo, fator determinante para a formação de escritoras nos territórios africanos, o que já se caracteriza como uma grande desvantagem sociocultural inclusive na contemporaneidade.

Além disso, outro grande fator impeditivo, é a questão racial na imbricação com o colonialismo, que perpassa as esferas já supracitadas. Mesmo que no continente africano as questões raciais sejam encaradas de maneira diversa do Brasil os de outros países americanos, naqueles espaços a mulher negra continua sendo pouco representada e valorizada enquanto escritora, pois a atividade intelectual 
que envolve o processo de escrita não é um papel ou função feminina em grande parte das culturas das nações. A realidade colonial e o processo do capitalismo global, mesmo que tenham trazido oportunidades materiais de escolarização para as mulheres negras que desejavam registrar histórias, ainda assim, ajudaram a perpetuar desigualdades já existentes nos entraves patriarcais tanto para a recepção quanto editoração de textos literários produzidos por mulheres. A experiência de Paulina Chiziane comprova esse argumento quando ela $\mathrm{diz}^{8}$ sobre as dificuldades, para as mulheres, de acesso e penetração nos espaços oficialmente reconhecidos para escritores em Moçambique.

Por isso, ao analisar as experiências romanescas de Paulina Chiziane em Moçambique e Sefi Atta na Nigéria, tais questões, do racismo, patriarcado, colonialismo e capitalismo global estarão imbricadas, pois a própria existência dessas escritoras em um mundo que, constantemente, oprime suas mais variadas formas de expressão, é determinante para a consolidação de seus escritos ficcionais.

É mister também explorar o contexto contemporâneo que abarca a realidades das mulheres em cada um dos países

8 Entrevista da escritora para o Brasil de Fato em 21 de setembro de 2016. Disponível em: https://www.youtube.com/watch?v=jF8WAxk3o-0\&t=4s Acesso em: 3 mar. 2021. 
para elucidar o contexto de produção literária das autoras. $\mathrm{Na}$ história de Moçambique é possível estudar muitos movimentos de mulheres, incluindo a luta pela libertação do país e, mais recentemente, a configuração em movimentos e organizações feministas. Atualmente, o país está no 16임 lugar no Monthly ranking of women in national parliaments ${ }^{9}$ em ocupação de cadeiras no Congresso Nacional, apresentando $42,4 \%$ de representação política de mulheres. No último pleito, o índice ainda aumentou e parte dessa participação remete ao envolvimento político em cargos de liderança, existente desde a luta pela libertação nacional contra o colonialismo e o patriarcado na esperança de participação igualitária entre os gêneros para a nova nação. Entretanto, muitas expectativas não se cumpriram e a representatividade parlamentar nem sempre oferece um diálogo aberto entre mulheres moçambicanas, pelo contrário, muitas vezes há conflitos de interesses ${ }^{10}$.

Do outro lado do continente, a Nigéria encontra uma realidade bem diferente e está na 185a posição ${ }^{11}$ de 9 Monthly ranking of women in national parliaments. Disponível em: https://data.ipu.org/ women-ranking?month=10\&year=2020. Acesso em: 5 mar. 2021.

10 Essa constatação foi elaborada pela socióloga moçambicana Isabel Casimiro no simpósio "Nós tantas outras" promovido pelo Sesc São Paulo em dezembro de 2018. As gravações podem ser conferidas em: https://www.sescsp.org.br/programacao/172731_NOS+TANTAS+OUTRAS. Acesso em: 05 mar 2021.

11 Apenas para se ter uma perspectiva comparativa, o Brasil (143a posição) está muito mais próximo da realidade nigeriana, as últimas eleições nacionais, em outubro de 2018 , alcançaram os inéditos números de 14,6\% de participação de mulheres na Câmara e 13,6\% no Senado. Vale 
representação política feminina com eleições em fevereiro de 2019 que apresentaram apenas 3,6\% de participação de mulheres no Baixo Parlamento e 7,3\% no Alto Parlamento. Por outro lado, as vozes feministas nigerianas têm alcançado cada vez mais repercussão internacional com iniciativas, movimentos e lideranças sociais, com mais visibilidade ao redor do mundo, tanto em publicações de ficção quanto em reportagens jornalísticas e textos de teorias sociais, históricas e políticas. Sobre esse viés, destaca-se aqui as reflexões sobre o feminismo do continente africano pelo olhar da ativista nigeriana Minna Salami:

The truth is that feminism is an absolute necessity for African societies. While the term 'feminism' is an import to Africa (as all English words are), the concept of opposing patriarchy, the raison d'être of feminism if you like, is not foreign. Africa has some of the oldest civilizations in the world so while they didn't always call it feminism (the noun) as far back as we can trace we know that there were women who were feminist (the adjective) and who found ways of opposing patriarchy. Feminism is an important part of African women's "herstory". (SALAMI, 2013)12

ressaltar também que o pleito foi polarizado e disputado, com grandes episódios de misoginia em oposição às lutas das mulheres para serem ouvidas e representadas.

12 A verdade é que o feminismo é uma necessidade absoluta para as sociedades africanas. [...] Enquanto a palavra "feminismo" é certamente uma importação (como todas as palavras em inglês), o conceito de oposição patriarcal, isto é, a raison d'être do feminismo, não é algo novo ou estranho no nosso continente. África tem algumas das civilizações mais antigas do mundo, por isso, embora nem sempre o chamassem de feminismo (o substantivo) até 
Historicamente, cabe ressaltar, são diversas os processos de colonização e independência entre Moçambique e Nigéria, além das origens sociais e étnicas de cada território. Porém, as questões trazidas por cada autora que será trabalhada neste artigo - seja de ordem religiosa, política ou institucional - podem ser aproximadas com bastante identificação. E é justamente a razão pela qual o diálogo entre as a escrita feminina de diferentes países acontece, pois, as realidades se encontram em condições econômicas e sociais muito próximas, pois essas escritoras estão, na contemporaneidade, imersas no capitalismo, no racismo e no patriarcado, sistemas sobre os quais reconhecemos seu campo ideológico.

A importância em destacar esses aspectos históricos, políticos e demográficos incide nas possibilidades e perspectivas que estão na base do projeto literário das autoras e na temática de suas obras. Torna-se, além disso, essencial considerar a imbricação entre gênero classe e raça, para a análise da literatura produzida no continente africano hoje. Por isso, é importante considerar a primorosa

onde podemos rastrear sabemos que havia mulheres que eram feministas (o adjetivo) e que encontraram maneiras de se opor ao patriarcado. Portanto, o feminismo é uma parte importante da história das mulheres africanas. [Tradução de Âurea Mouzinho] Disponível em: https://www.ondjangofeminista.com/ondjango/2017/4/10/reivindicando-o-espao-paranos-chamarmos-feministas-africanas. Acesso em: 19 nov. 2020. 
contribuição da ativista Angela Davis em sua obra Mulheres, raça e classe (2016), em que a ideia da intersecção entre essas categorias de análise são mútuas e cruzadas constantemente, para que se possa compreender a sociedade que vivemos e promover uma mudança significativa em direção à liberdade das opressões vividas.

Dessa forma, quando analisamos o projeto de escrita literária das autoras Paulina Chiziane e Sefi Atta, é perceptível a preocupação em retratar o universo das mulheres em Moçambique e na Nigéria, respectivamente, de forma alinhada política e ideologicamente na denúncia das lógicas de dominação e opressão que recaem sobre as trajetórias femininas. Essa marca perpassa não apenas as trajetórias das personagens nos seus principais romances, mas também a função e o trabalho da escritora na sociedade que vivem.

\section{PAULINA CHIZIANE E A EXPERIÊNCIA DA ESCRITA FEMININA EM MOÇAMBIQUE}

Analisar a ficção de Paulina Chiziane é conhecer as trajetórias das mulheres moçambicanas em variados tempos históricos. Mesmo denominando-se como contadora de histórias, ela é considerada a maior romancista de seu país, seu percurso literário é responsável por engajar a luta pelos direitos e sentidos das mulheres. Sobre esse tema, 
a escritora já foi questionada algumas vezes a respeito do posicionamento ideológico de sua literatura e não hesitou em responder que todas as suas obras são especialmente dedicadas ao universo da mulher ${ }^{13}$. Mesmo não assumindo um caráter feminista propriamente dito, grande parte de seus escritos e da construção de suas personagens orientam trajetórias feministas, no sentido de ser este um movimento que busca a libertação social das mulheres na conjuntura do sistema capitalista e patriarcal.

Chiziane, além de romances, tem uma vasta experiência na escrita de poemas, contos e ensaios, entre outros diversos textos que já foram traduzidos para inúmeras outras línguas e que, no Brasil, por sua vez, sempre encontraram ampla receptividade crítica. Por essa visibilidade, ela pode ser considerada, certamente, a escritora africana de língua portuguesa mais mencionada e conhecida.

Se formar como escritora, porém, não foi um percurso fácil na vida de Paulina, que cresceu durante o período colonial de Moçambique. Como assinala Pereira (2008), ela era filha de uma família de origem simples (seu pai era alfaiate e sua mãe camponesa) que se posicionava abertamente contra o regime dos assimilados na colônia portuguesa, fato que

13 Entrevista de Paulina Chiziane para a BBC Brasil. Disponível em: https://www.bbc.com/ portuguese/internacional-37734763. Acesso em: 8 fev. 2021. 
é crucial na construção de muitas das suas personagens literárias. Também foi educada na língua do colonizador e teve acesso à educação formal em escolas católicas e para brancos, mas morava em bairros suburbanos para negros não assimilados da cidade de Manjacaze, província de Gaza, sul de Moçambique. Ela chegou a cursar Linguística na Universidade Eduardo Mondlane em Maputo, capital, mas não concluiu o ensino superior.

Outro fator relevante para a construção das identidades da escritora é sua origem chope, um povo tradicionalmente agrário que foi dominado pelo reino de Gungunhana entre 1884 e 1894. Esse período, apesar de ser anterior ao nascimento de Paulina, foi extremamente determinante para a organização estrutural do sul de Moçambique e para o enfrentamento das tropas portuguesas. Já durante a colonização do século $X X$, quando os portugueses resolveram ocupar definitivamente o território, os chopes ficaram conhecidos por resistir à exploração portuguesa de diversas formas, seja pelo não pagamento de imposto, por reorganizações familiares propositais, descumprindo regras de plantio e colheita ou por meio de símbolos culturais. Um exemplo disso é uma série de $\operatorname{cantos}^{14}$ que denunciavam o

14 Ainda estamos furiosos; é sempre a mesma história: A filha mais velha tem de pagar o imposto; Natanele diz ao homem branco que o deixe em paz, Natanele diz ao homem branco que me deixe estar; Vocês, os anciãos, devem discutir os nossos assuntos, Pois o homem que 
regime colonial e o sistema dos coletores, na tentativa de proteger e libertar seus territórios da ofensiva colonial.

É válido ressaltar, em meio ao panorama histórico e social, que Paulina Chiziane, nascida em 1955, cresceu em um ambiente dividido pela consolidação do regime colonial português e pelo nascimento da luta armada que buscava a independência de Moçambique. De qualquer maneira, é fato que sua formação como contadora de histórias entre o povo chope foi extremamente relevante para sua carreira como escritora, como destaca laná de Souza Pereira em seu trabalho de doutorado que promove a escuta de escritoras:

Paulina se lembra que sua avó materna era uma célebre contadora de histórias: muita gente vinha de longe para ouvi-la. Eram histórias chopes que inspiraram muito sua escrita. Posto que considera que o cerne de sua escrita é a oralidade, ela não gosta de nenhuma palavra escrita que não possa ser ouvida, e esse é seu grande dilema ao escrever em português: as ideias mais belas e mais profundas Ihe vêm a mente na língua em que se formou, a língua dos chopes. É como se não conseguisse traduzir perfeitamente para o português - que aprendeu na escola - uma mensagem que deseja transmitir. Nesse processo de transpor ideias para o português, é como se tivesse de recriá-las em outra língua e, com isso, ela sente que

os brancos nomearam é filho de um zé -ninguém; Os Chope perderam o direito à sua própria terra. Deixem que Ihes conte [...] Canção retratada na obra Lutar por Moçambique de Eduardo Mondlane, publicada em 1969, alguns meses após sua morte. 
muitos valores se perdem. Assim, apesar da influência europeia que dominou seu país, Paulina é categórica: sua raiz é puramente africana. (PEREIRA, 2018, p. 50)

A atuação de Paulina como militante também merece destaque em sua biografia, participando da Frente de Libertação de Moçambique (FRELIMO) na luta armada nacionalista durante a guerra de independência de seu país, que se findou em 1975. Foi somente após essa experiência que a autora se dedicou a alguns projetos pessoais e políticos e conseguiu traçar seu percurso literário, o que pôde Ihe render, em 2005, uma indicação ao prêmio Nobel da Paz por seus trabalhos em prol da justiça e da igualdade em Moçambique e pela atenção dedicada às questões das mulheres de seu país.

Nesse sentido, no caminho de delinear aspectos sobre a produção de Paulina Chiziane ao longo dos últimos anos, evidencia-se um projeto literário calcado em tal luta: o de dar voz às mulheres moçambicanas inscritas na contemporaneidade sob determinadas estruturas sociais que as oprimem constantemente. Em 1992, ano do Acordo de Paz em Moçambique, a escritora testemunhou sobre a situação da mulher em uma fala que foi organizada no seguinte relato: “Eu, mulher... por uma nova visão de 
mundo", lido na Conferência Internacional da UNESCO sobre a Mulher, Paz e Desenvolvimento em Pequim em 1995. Em suas reflexões, ela diz:

Nós, mulheres, somos oprimidas pela condição humana do nosso sexo, pelo meio social, pelas ideias fatalistas que regem as áreas mais conservadoras da sociedade. [...] Pretendo revelar um pouco desta experiência sem falsidade nem superficialização, para quebrar o silêncio, para comunicar-me, para apelar à solidariedade e encorajamento das outras mulheres ou homens que acreditam que se pode construir um mundo melhor. (CHIZIANE, 2013, p. 200-201)

Revela-se, portanto, a constante afirmativa de Paulina de que não existe uma decisão deliberada em privilegiar determinado sexo na sua ficção, mas que, por ser mulher, narra sobre suas impressões e experiências e consegue, dessa maneira, captar e alcançar a vida de tantas outras mulheres circunscritas diante da mesma realidade. É visível, inclusive em seu trabalho como escritora, a opressão e o silenciamento feminino e como é necessário combatê-lo para alcançar um mundo menos desigual.

E será somente no contexto pós-independência que a escritora vai concentrar suas publicações romanescas. Uma das chaves de leitura para seu projeto literário evidencia de que forma os ideais revolucionários ainda tão recentes 
não apenas foram enfraquecidos, mas acabaram se abrindo para o capitalismo vigente pós segunda guerra mundial, colocando as mulheres, anteriormente protagonistas dos anseios nacionalistas em Moçambique, em situação de subalternidade, vulnerabilidade e esquecimento. Esse, aliás, é o cenário histórico de seu primeiro romance publicado, quando ela tinha trinta e cinco anos e Moçambique findava uma guerra de desestabilização, ${ }^{15}$ entre os movimentos políticos da FRELIMO e da RENAMO (Resistência Nacional Moçambicana).

Recebendo o nome de Balada de amor ao vento, publicado em 1990, a obra apresenta-nos a protagonista Sarnau, alguém que demonstra coragem e força ao lidar com a temática do abandono, tanto político quanto amoroso. As clivagens entre o sistema colonial e a subjetividade, colocam o papel social do feminino sempre em relação de subalternidade e os discursos patriarcais reforçam a identidade 'natural' desse caráter alimentado pelas estruturas de poder. Apesar dos percalços sociais e familiares, a voz colocada na trajetória da personagem

15 A ideia de uma guerra de desestabilização é utilizada para caracterizar os conflitos do período pós-independência devido ao caráter de crise política e econômica desencadeada pela instabilidade do Estado moçambicano. Uma entrevista com o historiador moçambicano Egídio Vaz em De guerra de desestabilização a guerra civil: historiador moçambicano fala sobre o conflito entre a Frelimo e a Renamo "Uma viagem, muitos balanços" - 20 anos de paz em Moaçambique. Deustche Welle Africa, 2 out. 2012. Disponível em: https://www.dw.com/pt-002/de-guerra-dedesestabiliza\%C3\%A7\%C3\%A3o-a-guerra-civil-historiador-mo\%C3\%A7ambicano-fala-sobre-oconflito-entre-a-frelimo-e-a-renamo/a-16262237. Acesso em: 3 mar. 2021. 
discute e questiona o sentimento amoroso e as relações entre homens e mulheres diante da conjuntura histórica de Moçambique e - vale lembrar - é pela primeira vez que a perspectiva feminina se encontra com a escrita romanesca em língua portuguesa oriunda de uma mulher daquele país.

Após sua estreia, Paulina ainda publica outros inúmeros textos em prosa que abarcam diferentes perspectivas moçambicanas. Ainda depois de Ventos do apocalipse (1999) e O sétimo juramento (2000), a escritora recebe um prêmio pela obra Niketche: uma história de poligamia, em 2002 e agracia o público alguns anos depois com $O$ alegre canto da perdiz já em 2008. Todos os romances apresentam protagonismo de mulheres, porém, enquanto os primeiros centram o enredo na guerra, nas tradições, religiões e encontros entre culturas europeias e africanas diante dos desafios nacionais perante a nova questão mundial, os últimos apresentam-se como grandes apostas para seu percurso literário preocupado com a condição e movimentos de mulheres.

Com a personagem Rami em Niketche: uma história de poligamia, Paulina ousa retratar a questão da poligamia para as sociedades ao sul de Moçambique sobre o olhar e a voz de uma mulher que vivencia essa experiência em 
um contexto muito atual. Decerto, a obra causou uma grande polêmica no país e uma nova inquietação para a crítica literária feminista, que poderia partir de uma perspectiva endógena sobre a poligamia e a monogamia e de que forma essas relações conjugais afetam a mulher inserida nas práticas de poder, que, de uma forma ou de outra, privilegiam o homem. O fato é que, o modo como a personagem entende e desenvolve sua trajetória no romance, questiona as estruturas patriarcais existentes, a ruptura familiar e a realização cotidiana, além de inaugurar uma nova independência para as mulheres. O livro é, de fato, parte fundamental da organização literária em torno da qual se ergue uma estrutura de enfrentamento do sistema patriarcal.

Em seu último romance publicado ${ }^{16} \mathrm{O}$ alegre canto $d a$ perdiz, a própria estrutura da narrativa também se vincula ao projeto literário de dar voz às mulheres moçambicanas. Ao misturar a trajetória de diversas personagens, especialmente Delfina e Maria das Dores, com fábulas e mitos de fundação sobre a história de Moçambique, da Zambézia e da relação 16 Paulina também publicou desde 2008, outras obras, como: as heroínas sem nome memórias de guerra e paz das mulheres em Angola, em parceria com Dya Kassembe (2008), o livro de contos As andorinhas (2009), o texto Eu mulher... por uma nova visão de mundo (2013), as obras Na mão de Deus (2013), Por quem vibram os tambores do além (2013), Ngoma Yethu: O curandeiro e o novo testamento (2015) e o livro de poemas O canto dos escravos (2017). Suas publicações entre 2013 e 2015 contam com a coautoria de uma médium, um curandeiro e uma curandeira e circundam sobre questões de espiritismo e feitiçaria em Moçambique. A própria escritora não define as obras como romances. 
entre homens e mulheres, o enredo apresenta diversos sentidos que coincidem com momentos históricos em que as mulheres buscam, em forma de diálogo, resgatar seu passado para a compreensão das demandas do presente.

É evidente que, na marca da voz e da corporeidade das personagens femininas de $O$ alegre canto da perdiz, há uma denúncia da opressão vivida pelas mulheres moçambicanas ao longo dos principais movimentos históricos, como o casamento forçado, o estupro, a sobrecarga de tarefas práticas e emocionais, o sustento da família etc. O período do colonialismo português, a forte influência das religiões cristãs, o capitalismo, o patriarcado e, inclusive, os novos movimentos de globalização, condicionam as mulheres a novos papeis de subordinação. A narrativa e as personagens questionam essas premissas o tempo todo, tentando ressignificar tais demandas a cada circunstância.

De fato, o percurso voltado aqui à literatura romanesca de Paulina Chiziane mostra de que forma a escritora é engajada política e socialmente com as mulheres moçambicanas, buscando refletir sobre as lutas, direitos e desafios da contemporaneidade em constante diálogo com pautas de reivindicação dos direitos das mulheres ao redor do mundo e com o próprio lugar da escrita elaborada por mulheres de 
seu país. Por isso, a crítica literária deve estar consciente que a escrita de Paulina está comprometida com a libertação das mulheres moçambicanas - e de todas as mulheres - em todas as experiências romanescas da autora.

\section{A EXPERIÊNCIA DE SEFI ATTA COMO ESCRITORA NIGERIANA}

Sefi Atta talvez não seja o nome mais conhecido da literatura nigeriana que é publicada no Brasil hoje. Em meio a nomes como Chimamanda Ngozi Adichie, Buchi Emecheta e Adebayo Ayobami que tornaram-se sensação para o campo das literaturas estrangeiras por aqui, com publicações relevantes e grande público leitor, Sefi, que nasce em Lagos, na Nigéria, em 1964, escreve seu romance de estreia Everything good will come ${ }^{17}$ em 2005, porém, apesar da obra já ter sido premiada com o "Wole Soyinka de Literatura Africana"18, a edição brasileira do texto chega quase dez anos depois e, apenas com a reedição em 2020, por parte de um clube de assinatura de $\operatorname{livros}^{19}$, ela finalmente ganha mais projeção no território nacional, assim como as demais escritoras supracitadas. De qualquer

17 A última edição em língua inglesa foi publicada em 2019 pela Myriad Editions em Oxford, Inglaterra. ATTA, Sefi. Everything good will come. Oxford: Myriad Editions, 2019 e a tradução brasileira, baseada na primeira edição, é da Editora Record de 2013.

18 Everything good will come foi o primeiro livro a ser premiado com o Wole Soyinka, que leva esse nome em homenagem a outro grande escritor do país nigeriano, autor de: Os intérpretes (1980), O Leão e A Jóia (1986) e Melhor partires de madrugada (2008).

19 A reedição do livro de Sefi Atta foi resultado da curadoria da nigeriana Adebayo, Ayobami, que escreveu seu romance Fique comigo com grande sucesso entre os leitores do referido clube. 
forma, Atta faz parte de uma chamada "nova geração de autores nigerianos", alicerçados por célebres precursores, como Chinua Achebe.

A autora, que vem de uma família com origens iorubás, estudou em colégios nigerianos, mudou-se primeiramente para Inglaterra para fazer faculdade (formando-se em administração) e depois para os Estados Unidos, onde estudou Escrita Criativa e reside desde 1994. Após seu primeiro livro, ela também publicou outros romances: em 2010, Swallow, três anos depois, A Bit of Difference e, recentemente, a obra The Bead Collector, todos ainda inéditos no Brasil. Além dos romances, a autora é conhecida por seus roteiros premiados, peças teatrais encenadas internacionalmente, radionovelas famosas, contos diversos e um livro infantil, dividindo seu tempo também com sua produtora em Lagos que atua junto à instituições do país com projetos de leituras encenadas. A autora declara em sua página ${ }^{20}$ que acredita no poder e na importância do ofício da escrita como processo importante para que todas as histórias possam ser contadas sem silenciamentos.

E é justamente esse o projeto literário que incide sobre seu processo criativo ficcional e até para a construção de suas personagens, como é possível observar no trecho em 20 Página da autora: http://www.sefiatta.com/. 
que Grace Ameh salienta para Enitan, a protagonista do já referido primeiro romance: "No país em que vivemos, onde as palavras são tão facilmente eliminadas de nossa Constituição, de publicações e registros públicos, o ato de escrever é ativismo" (ATTA, 2013, p. 286).

Toda a trajetória literária de publicação da autora acontece em um período mais recente da história da Nigéria, um país que, diferentemente de Moçambique em relação aos processos de independência, teve dificuldades imensas de se constituir enquanto nação devido à falta de coesão entre seus povos, enfrentando, assim, inúmeras tensões e guerras separatistas de territórios (considerando as maiores populações: fulanis, hauças, iorubás e ibos). Dessa forma, o arranjo histórico e cultural do país foi sempre estabelecido politicamente desde a sua independência:

Quanto à independência, ficou agendada para $1^{\circ}$ de outubro de 1960 , em uma cerimônia considerada uma verdadeira caricatura das relações entre Grã-Bretanha e Nigéria naquele momento. Nela, o Dr. Margai, representando o governo da Nigéria, deu o braço à Sua Majestade, a Rainha Isabel. Assim, a política pragmática britânica deu ensejo para que se formasse uma imagem resumida na ideia de "partir para melhor ficar". (HERNANDEZ, 2008, p. 202) 
De acordo com o exposto, a política extremamente pragmática na independência da Nigéria, que também se distancia a realidade nigeriana da moçambicana, culminaram na independência do país em 1960 a partir de acordos e reformas políticas determinadas pelos britânicos, que conduziram todo o processo com a pretensão de gerenciar suas partes e manter relações econômicas com certa vantagem. Após momentos de muita tensão, como a Guerra da Biafra entre 1967 e 1970, a reunificação da Nigéria contou com diferentes partidos políticos, de distintas matrizes ideológicas e culturais, que disputavam e ainda questionam o poder e os territórios de acordo com concentração de riquezas e interesses econômicos.

Esse espaço em constante conflito compartilha, em certa medida, insatisfações políticas relacionadas ao colonizador e necessidades de mobilizações sociais. De maneira análoga, as confluências do patriarcado, do racismo e da estrutura colonial encontram, no constante contexto de opressão, variadas formas de incidir sobre os sujeitos históricos e tendem a silenciar narrativas que poderiam questionar e reavaliar as determinações. É sobre esse contexto que os romances de Sefi Atta ganham ainda mais projeção quando analisados sob a perspectiva da importância da escrita feminina. 
As imbricações entre história e literatura também garantem até mesmo a organização dos romances de Atta, pois os capítulos se seu primeiro livro, Everything good will come recebem como título alguns dos anos cruciais para as questões políticas da Nigéria pós-independência, conhecidos como período das Juntas Militares (1970 a 1999) ${ }^{21}$. O ambiente da cidade de Lagos, a metrópole do lado ocidental do continente, que até 1991 foi a capital do país, é determinante para a circulação dos anseios das personagens. Mas é justamente a perspectiva de uma mulher, que mobiliza todas as suas relações para, enfim, descobrir seu lugar, que revela o poder de diálogo entre o projeto literário da escritora e a necessidade de contar novas histórias que perpassam aquele tempo e espaço narrado.

Já no romance Swallon, a década de oitenta é marcada pela forte repressão e austeridade política em Lagos. Como efeito, as alternativas de vida para a protagonista Tolani - e para as mulheres de maneira geral - tornam-se cada vez mais restritas. Apesar de um texto centrado na autodescoberta da personagem, é a inserção dela enquanto mulher em uma sociedade patriarcal e capitalista que a leva aos piores caminhos possíveis. Uma narrativa que

21 FALOLA, Toyin. ADERINTO, Saheed. Nigeria, Nationalism, and Writing History. Rochester, NY: Boydell \& Brewer, Ltd, 2011. 
potencializa a experiência de Atta de elucidar as tentativas de sobrevivência de mulheres em um campo de opressões.

No mesmo sentido e dialogando diretamente com o primeiro romance e com a biografa da própria autora, A Bit of Difference é um livro que delimita o globalizado território da Nigéria hoje, com a apresentação de Deola Bello como protagonista, que vai da Nigéria para Inglaterra e carrega as aproximações e distanciamentos que marcaram a relação colonial entre os países no percurso histórico de sua própria vida material. Hoje, a autora de cinquenta e sete anos também divide seu tempo entre o continente africano e o americano e, dessa maneira, consegue realizar pontes subjetivas e objetivas que afetam as realidades de cada país.

Já em sua mais recente publicação, o romance The Bead Collector, é possível perceber, como pano de fundo histórico, o período dos duros regimes militares após a década de setenta, centrando o panorama narrativo ao redor de Remi Lawal, cujos conflitos sociais e econômicos estão em constante diálogo com a crise de seu país. Por isso, a Nigéria é também uma personagem central para esse texto, colocando-se como o lugar explorado do mundo capitalista e globalizado, mas que precisa se organizar para além de suas diferenças na tentativa de validar-se pelo 
sistema capitalista contemporâneo. Sefi Atta, com sua última obra no gênero publicada, posiciona novamente as mulheres diante dos conflitos de seu país, colocando as questões da maternidade, dos relacionamentos, do casamento e do próprio acesso à educação para as mulheres como centrais para as necessidades do território nigeriano.

Diante dessa trajetória pela experiência romanesca de uma das mais promissoras autoras nigerianas da atualidade, evidencia-se a necessidade de dar voz às mulheres para que outras histórias sejam contadas. A escrita de mulheres em territórios africanos garante a pluralidade, parafraseando, então, a conterrânea de Atta, Chimamanda Ngozi Adichie, em sua palestra "The danger of a single story" no TED Talks (2009), entrar em contato com essas literaturas é um caminho para que não tenhamos o perigo de uma única história sendo contada. ${ }^{22}$

Mesmo sem a quantidade de livros acessíveis a leitores brasileiros que possui Paulina Chiziane, a escritora nigeriana também se lança a um projeto literário que visibiliza sua escrita em favor das demandas das mulheres no continente africano. Ao somar duas vozes entre outras tantas histórias femininas pelo mundo, é possível vislumbrar um caminho

22 ADICHIE, Chimamanda Ngozi. "The danger of a single story" Ted Talks. 2009. Disponível em: $\mathrm{http}: / /$ www.ted.com/talks/chimamanda_adichie_the_danger_of_a_single_story?language=ptbr. Acesso em: 6 mar. 2021. 
em que a escrita de mulheres se projete para além das trincheiras sociais.

\section{CONSIDERAÇÕES FINAIS}

Enquanto Paulina Chiziane é considerada veterana romancista das literaturas africanas em língua portuguesa, Sefi Atta ainda é pouco reconhecida dentro da crítica literária sobre os romances nigerianos em língua inglesa. A primeira já foi até alvo de polêmicas por seus temas que envolvem as relações pessoais, como a poligamia, e os conflitos culturais entre norte e sul de Moçambique. Já para o contexto nigeriano, a segunda autora destacase nas temáticas da interlocução entre os papeis sociais desempenhados pelas mulheres nigerianas e a colocação do próprio país no contexto global.

Apesar de alguns distanciamentos que podem ser observados entre a escrita de Sefi Atta, que até mesmo pela sua trajetória pessoal, parece ser direcionada para um público de fora da Nigéria, enquanto Paulina Chiziane se concentra na vivência moçambicana mais íntima, ambas posicionam o projeto político de seus escritos ficcionais privilegiando as mulheres em suas demandas e lutas nos territórios africanos diante da contemporaneidade. Ambas são escritoras responsáveis por apresentar-nos um projeto 
literário que privilegia a presença e a luta das mulheres em seus territórios.

O fato é que o campo ideológico, de valores e ideias do sistema patriarcal e capitalista não são suficientes para atender demandas da literatura e da própria vida das escritoras, então elas reproduzem, no campo literário, um projeto literário romanesco que levanta questões e análises sobre suas condições materiais e históricas. Isso acontece pelo fato de que, as mulheres, por estarem na esteira do capitalismo e do patriarcado, se colocam e constroem seus romances e personagens colocando-se nas trincheiras dos embates.

Soma-se ainda o fato de ambas serem escritoras negras em um universo racista em países que não apenas sofreram processos intensos de colonização, mas que também tiveram suas populações originais expurgadas para outros continentes em um intenso tráfico de pessoas escravizadas. Todas as experiências colocadas pelas mulheres negras perpassam a ficção das escritoras que inserem suas personagens, também negras, para se projetarem como vozes potentes na concretização de suas próprias histórias.

Escolhendo a forma do romance como gênero literário capaz de elucidar as trajetórias das personagens circunscritas 
e das próprias experiências enquanto escritoras, Paulina e Sefi podem, assim, colaborar com leituras sobre a potencialidade da escrita de mulheres ontem e hoje a partir de suas realidades materiais.

\section{REFERÊNCIAS}

ADICHIE, Chimamanda Ngozi. The danger of a single story. Ted Talks. 2009. Disponivel em: http://www.ted.com/talks/chimamanda_adichie the danger of a single story?language=pt-br Acesso em: 6 mar. 2021 ATTA, Sefi. Everything good will come. Oxford: Myriad Editions, 2019. ATTA, Sefi. Tudo de bom vai acontecer. São Paulo: Editora Record, 2013. ATTA, Sefi. Swallow. Northampton: Interlink Books, 2012. ATTA, Sefi. A Bit of Difference. Northampton: Interlink Books, 2012. ATTA, Sefi. The Bead Collector. Northampton: Interlink Books, 2018. BARROSO, Marta. Egídio Vaz em De guerra de desestabilização a guerra civil: historiador moçambicano fala sobre o conflito entre a FRELIMO e a RENAMO: uma viagem, muitos balanços - 20 anos de paz em moçambique. Deustche Welle Africa, 2 out. 2012. Disponível em: https:// www.dw.com/pt-002/de-guerra-de-desestabiliza\%C3\%A7\%C3\%A3oa-guerra-civil-historiador-mo\%C3\%A7ambicano-fala-sobre-o-conflitoentre-a-frelimo-e-a-renamo/a-16262237. Acesso em: 3 mar. 2021. BRASIL. Lei 10.639 de 9 de janeiro de 2003. D.O.U. de 10 de janeiro de 2003.

BDF Entrevista. Brasil de Fato em 21 de setembro de 2016. Disponível em: https://www.youtube.com/watch?v=jF8WAxk3o-0\&t=4s. Acesso em: 3 mar. 2021.

CASIMIRO, Isabel. Movimentos de Mulheres em Culturas Diversas. Mesa redonda promovida pelo Encontro Internacional Nós tantas outras. SESC, 2018. Disponível em: https://www.sescsp.org.br/online/artigo/12772 MESAS+DE+DEBATE+NOS+TANTAS+OUTRAS. Acesso em: 5 mar. 2021. 
CHIZIANE, Paulina. O alegre canto da perdiz. Lisboa: Editorial Caminho, 2008.

CHIZIANE, Paulina. Balada de amor ao vento. Lisboa: Editorial Caminho, 2003.

CHIZIANE, Paulina. Niketche. Uma história de poligamia. Lisboa: Editorial Caminho, 2002.

CHIZIANE, Paulina. O sétimo juramento. Lisboa: Editoral Caminho, 2000.

CHIZIANE, Paulina. Ventos do apocalipse. Lisboa: Editorial Caminho, 1999.

CHIZIANE, Paulina. Eu, mulher... por uma nova visão do mundo. Abril Revista do Núcleo de Estudos de Literatura Portuguesa e Africana da UFF. Rio de Janeiro, n. 10, p. 199-205, 2013.

CISNE, Mirla. Marxismo: uma teoria indispensável à luta feminista. Disponível em: http://www.unicamp.br/cemarx/ANAIS\%20IV\%20COLOQUIO/ comunica\%E7\%F5es/GT4/gt4m3c6.PDF. Acesso em: 20 fev. 2021.

DAVIS, Angela. Mulheres, raça e classe. São Paulo: Boitempo editorial, 2016.

EAGLETON, Terry. Teoria da Literatura: Uma Introdução. São Paulo: Martins Fontes, 2011.

FAGUNDEZ, Ingrid. Entrevista de Paulina Chiziane para a BBC Brasil. Disponível em: https://www.bbc.com/portuguese/ internacional-37734763. Acesso em: 8 fev. 2021.

FALOLA, Toyin. ADERINTO, Saheed. Nigeria, Nationalism, and Writing History. Rochester, NY: Boydell \& Brewer, Ltd, 2011.

HERNANDEZ, Leila Leite. HERNANDEZ, Leila Maria Gonçalves Leite. A África na sala de aula: visita à história contemporânea. São Paulo: Selo Negro, 2005.

IPU Parline. Monthly ranking of women in national parliaments. Disponível em: https://data.ipu.org/womenranking?month=10\&year=2020. Acesso em :19 nov. 2020. LISPECTOR, Clarice. Amor. In: LISPECTOR, Clarice. Laços de Família. Rio de Janeiro: Rocco, 1998. 
LUKÁCS, Georg. A teoria do romance. São Paulo, Editora 34, 1999. MONDLANE, Eduardo. Lutar por Moçambique. Lisboa: Sá da Costa Editora, 1975

MOUZINHO. Áurea. Reivindicando o espaço para nos chamarmos Feministas Africanas: Apresentação e suplemento à tradução do texto de Minna Salami. In: MOUZINHO. Áurea. Uma breve história do feminismo africano. Angola: Ondjango Feminista, 2017. Disponível em: https://www.ondjangofeminista.com/ondjango/2017/4/10/ reivindicando-o-espao-para-nos-chamarmos-feministas-africanas. Acesso em: 5 mar. 2021.

NICHOLS, Catherine. Homme de Plume: What I Learned Sending My Novel Out Under a Male Name. In: JEZEBEL. A Supposedly Feminist. Disponível em: https://jezebel.com/homme-de-plume-what-i-learnedsending-my-novel-out-und-1720637627. Acesso em: 3 mar. 2020. NUNES, Maria Aparecida. Dissimulações de Clarice Lispector. Olho d'água. São José do Rio Preto, v. 2, n. 2, p. 66-77, 2010.

PEREIRA, laná de Souza. De contos a depoimentos: memórias de escritoras negras brasileiras e Moçambicanas. 2018. Tese (Doutorado) Universidade de São Paulo, São Paulo, 2018.

SAFFIOTTI, Heleieth. Gênero, patriarcado e violência. São Paulo: Editora Expressão Popular, 2004.

SOARES, Cláudia Regina. CARBONIERI, Divanize. Nervous conditions: a literatura africana escrita por mulheres e o tema da educação formal. UFMA/Campus III, v. 1, n. 3, p. 133-156, outubro/dezembro de 2016. STRATTON. Florence. Contemporary African literature and the politics of Gender. New York: Routledge, 1994.

WOOLF, Virginia. Um teto todo seu. São Paulo: Editora Tordesilhas, 2014.

\section{Stela Saes}

Mestra. USP. Literaturas africanas, estudos comparados, literatura, feminismo e história.

Participação no grupo de Pesquisa Núcleo Brasil África - Universidade 
de São Paulo. Literaturas africanas de língua portuguesa, Estudos Comparados, Literatura, Feminismo, História.

Lattes: http://lattes.cnpq.br/1399489912142103

E-mail: stela.saes@usp.br

ORCID iD: https://orcid.org/0000-0003-3741-6061 